\title{
AC 2009-868: ASSESSMENT OF ENGINEERING EXPERIMENTATION AND INSTRUMENTATION
}

\section{Mysore Narayanan, Miami University}

DR. MYSORE NARAYANAN obtained his Ph.D. from the University of Liverpool, England in the area of Electrical and Electronic Engineering. He joined Miami University in 1980 and teaches a wide variety of electrical, electronic and mechanical engineering courses. He has been invited to contribute articles to several encyclopedias and has published and presented dozens of papers at local, regional, national and international conferences. He has also designed, developed, organized and chaired several conferences for Miami University and conference sessions for a variety of organizations. He is a senior member of IEEE and is a member of ASME, SIAM, ASEE and AGU. He is actively involved in CELT activities and regularly participates and presents at the Lilly Conference. He has been the recipient of several Faculty Learning Community awards. He is also very active in assessment activities and has presented more than a dozen papers at various Assessment Institutes. His posters in the areas of Bloom's Taxonomy and Socratic Inquisition have received widespread acclaim from several scholars in the area of Cognitive Science and Educational Methodologies. He has received the Assessment of Critical Thinking Award twice and is currently working towards incorporating writing assessments that enhance students' critical thinking capabilities. 


\title{
Assessment of Engineering Experimentation and Laboratory Instrumentation
}

\begin{abstract}
The artistic science of measurement and control is normally referred to as Instrumentation. The varied attributes of physical systems are usually measured using well designed instruments. A small list may include voltage, current, resistance, inductance, capacitance, frequency, pressure, stress, strain, viscosity, flow, radiation, etc. Instruments are normally modeled as simple input-output devices. The author taught a new course in the area of Engineering Instrumentation during 2005 - 2006 and experimented with some new ideas. He also successfully designed, developed and implemented certain assignments and exercises to enhance student learning and discovery. In this course, the author attempted to move away from a teaching and learning paradigm to a discovery paradigm. This is a junior/senior level course which also includes a set of creative laboratory experiments that aim at providing hands-on experience to students. As a part of this course curriculum development, the author implemented certain assessment techniques. In this presentation the author describes how he assessed the outcomes for selected topics in this specific course. He also provides and some data he has collected and provides suggestions for further improvement.
\end{abstract}

\section{Introduction}

Utilizing real-world problems as a stimulus for student learning is not at all new and has been in practice for a very long time. Problem-based learning has been defined as minds-on, hands-on, focused, experiential learning. (Wilkerson \& Gijselaers, 1996). A problem-based curriculum is significantly different from the traditional discipline centered curriculum. (Woods, 1994). Instructors are considered to serve as problem solving colleagues assigned with the responsibility of promoting interest and enthusiasm for learning (Narayanan, $2005 \& 2006$ ). Instructors are also encouraged to act as cognitive coaches who can nurture an environment that can support open inquiry. (Barrows, 2000). It is important that the aims and objectives of problem-based learning are reflected in every aspect of the learning environment created. Problem-based curriculum should document accomplishments at the upper levels of Bloom's Taxonomy Triangle. (Boud \& Feletti, 1991). Scholars in the area of cognitive science and educational psychology have identified four features that clearly separate a problembased curriculum from a traditional, topic-based curriculum. (Nickerson, et. al. 1985). In this presentation, the author describes how he has utilized the four features in the course he teaches. He also presents analyses of the feedback data he has obtained and suggests guidelines for further improvement (Narayanan, 2007 \& 2008).

\section{Four Features of Learning:}

Scholars have identified four features that clearly separate a problem-based curriculum from a traditional, topic-based curriculum (Narayanan, 2007 \& 2008).

[http://www.cmu.edu/teaching/principles/learning.html] 


\section{Learning must be cumulative:}

The subject matter is not learned by the student in great depth at one long stretch. On the contrary, the topics are introduced gradually and repeatedly. Furthermore, the level of complexity of subject matter should increase with the progression of time.

\section{Learning must be integrated:}

The subject matter is must not introduced with a stand-alone approach. Topics are always discussed as the correlate to a real world problem.

\section{Learning must be progressive:}

The student's learning keeps changing continuously. Learners begin acquiring specific skills and knowledge of subject matter. As time progresses, this knowledge base is expanded and integrated with what has already been learnt.

\section{Learning must be consistent:}

The learning environment created should ensure repeatability. Every learner should accomplish identical goals and educational outcomes. Individual learning styles should have no impact on the knowledge acquired.

\section{Instructional Systems Design}

The principle behind a well structured Instructional Systems Design is to ensure that the subject matter content is effectively integrated with the presentation format. The task in front of the facilitator will be blend the content and presentation in theory as well as practice (Dick and Carey, 1978). Modern technology provides ample opportunities for the instructors to experiment on innovative ideas that can lead to effective classroom instructional strategies (Dick and Carey, 1996). Instructional Systems Design (ISD) was made popular by Walter Dick and Lou Carey whose famous quote is: "You can't provide a solution until you know what the problem is." (Narayanan, $2007 \& 2008)$. One can conclude that learning has taken place when the instructor observes a change of learner behavior (Keefe, 1988). This learner behavior must be the result of what has been experienced in the process of instruction (Pascarella \& Terenzini, 1991). One can also recognize that the learning style of an individual student only by observing his/her overt behavior (Keefe 1987). It is also important to identify that in order to develop a sense of agency, student affairs professionals must possess four dimensions of learning that specify desired outcomes: cognitive competence, intrapersonal competence, interpersonal competence, and practical competence (Baxter Magolda, 1999). 


\section{Implementation and Assessment}

The author utilized Washington State University's Critical Thinking Rubric to correlate assessment to grading. The manner in which this was implemented is documented in Appendix A - D. In this particular example, the assessment documentation was carried out in the subject matter area of Engineering Experimentation (Narayanan, 2007 \& 2008).

Appendix A shows how data collection was correlated to assessment. The grading was administered using Washington State University's Rubric. Rubrics offer help and challenge the user to determine the levels of growth and learning that would be assessed as well as the methods to assess student learning at various stages (Bresciani, 2003).

A sample matrix is shown in Appendix B. The data obtained was tabulated using a Likert Scale. Several "Primary Traits" or "Characteristics" were identified and assessed. These are the major topics that are to be covered in any Engineering Experimentation or Instrumentation Course. The author chose seven, however another instructor may choose more or less.

Appendix $\mathrm{C}$ documents this using a bar chart. It is desirable to achieve mode values of 5 on all the seven characteristics; however this is probably unrealistic in an undergraduate environment (Narayanan, 2005, 2006, 2007 \& 2008).

The author would like to thank Washington State University for providing him with guidance and Rubrics to prepare this document. Washington State University's Critical Thinking Rubric has proved to be an extremely valuable in documenting teaching effectiveness. The author has used this rubric multiple times in his research and other publications (Narayanan, 2005, 2006, 2007 \& 2008).

This has helped the instructor address and assess perceptual dimensions of learning and thereby giving the learning environment facilitators appropriate guidance for proceeding in the right direction. The ultimate goal is to deliver information to students, not just in plain lecture format. But to provide the material in the best possible manner that suits the receiver's optimum learning style (Narayanan, 2005, 2006, $2007 \& 2008$ ). The author likes to move away from a teaching or learning paradigm. Instead, the author prefers that the students follow a Discovery Paradigm.

At Miami University, the author has tried to implement ideas from these scholars of Cognitive Science into practice using modern technology. This includes the World Wide Web, I.V.D.L. (Interactive Video Distance Learning) in addition to regular and routinely used audio visual techniques.

The author utilizes a variety of instructional tools (Lectures, Audio-visual aids, Power Point Presentations, Tutorials, Problem-solving sessions, written research reports, peer group discussions, etc.) to communicate with students who may prefer to have different 
learning styles. The author also recommends that students utilize the resources that are readily available at the university, such as Library. Writing Center, etc.

\section{Observations}

It is easily seen from the bar chart that one of the seven "traits" Characteristic \# 4 (Importance of Electrical and Electronic Instruments) shows excellent mode value of 5.

However, three other characteristics show respectable mode values of 4 indicating that attempts should be made to achieve the maximum value of 5. These three characteristics are:

Characteristic \# 2: Mechanical Transducers and Instrumentation

Characteristic \# 3: Heat Conduction Gages, Principles of Heat transfer

Characteristic \# 6: Skillful use of Potentiometers and L.V.D.T.s

However,

Characteristic \# 5: Ability to use Electromechanical Transducers and

Characteristic \# 7: Knowledge of Gages and Manometers

Both recorded mode value of 3 indicating that there is room for improvement.

Lowest score of 2 was recorded for Characteristic \# 1: Data Acquisition and Mathematical Analysis.

This shows that the students need broader exposure in the area of Mathematics.

Such assessment data provides the instructor to make appropriate changes in the manner in which the course is developed and may necessitate changes in Instructional Delivery Styles. Furthermore it should be recognized that each discipline is different and the difference may be huge and significant (Keefe, 1991). Each instructor's delivery style is different and one may even arrive at two different sets of data for the same subject and topic when two different instructors are involved.

\section{Conclusions}

Based on the data presented here and based on the data presented at previous ASEE conferences (Narayanan, 2005, 2006, 2007 \& 2008) the author arrives at the following conclusions (A.C.P. 2004).

1. Learning is to be viewed as a transformative process. It should react and respond to the student as a whole. 
2. Student development should focus on comprehensive learning and in an integrated environment.

3. Establishment of educational partnerships as opposed to passive learning environments shall be the main focus of faculty and administrators.

4. Knowledge can be acquired only by Active Processing of Information. Routine lectures, memorization of facts may not be that important.

5. Knowledge is essential. One can demonstrate expertise in performance by building on the solid foundation of what one already knows.

\section{Acknowledgements}

Dr. Mysore Narayanan is extremely grateful to the Center for the Enhancement of Learning and Teaching and Committee for the Enhancement of Learning and Teaching for granting him the award: "Senior Faculty Learning Community to Promote and Cultivate Intellectual Curiosity among Students" award. Dr. Narayanan also thanks Dr. Milt Cox, Director of Center for the Enhancement of Learning and Teaching at Miami University for his valuable suggestions and guidance. The author is extremely grateful to Dr. Gregg W. Wentzell, Managing Editor for the Journal on Excellence in College Teaching for his invaluable input. The author also thanks Dr. Paul Anderson, Director, Roger and Joyce Howe Center for Writing Excellence for his valuable input. 
APPENDIX A: (Methodology for conducting assessment using grades)

The author has previously used this 'cycle' in other research and publications, as well.

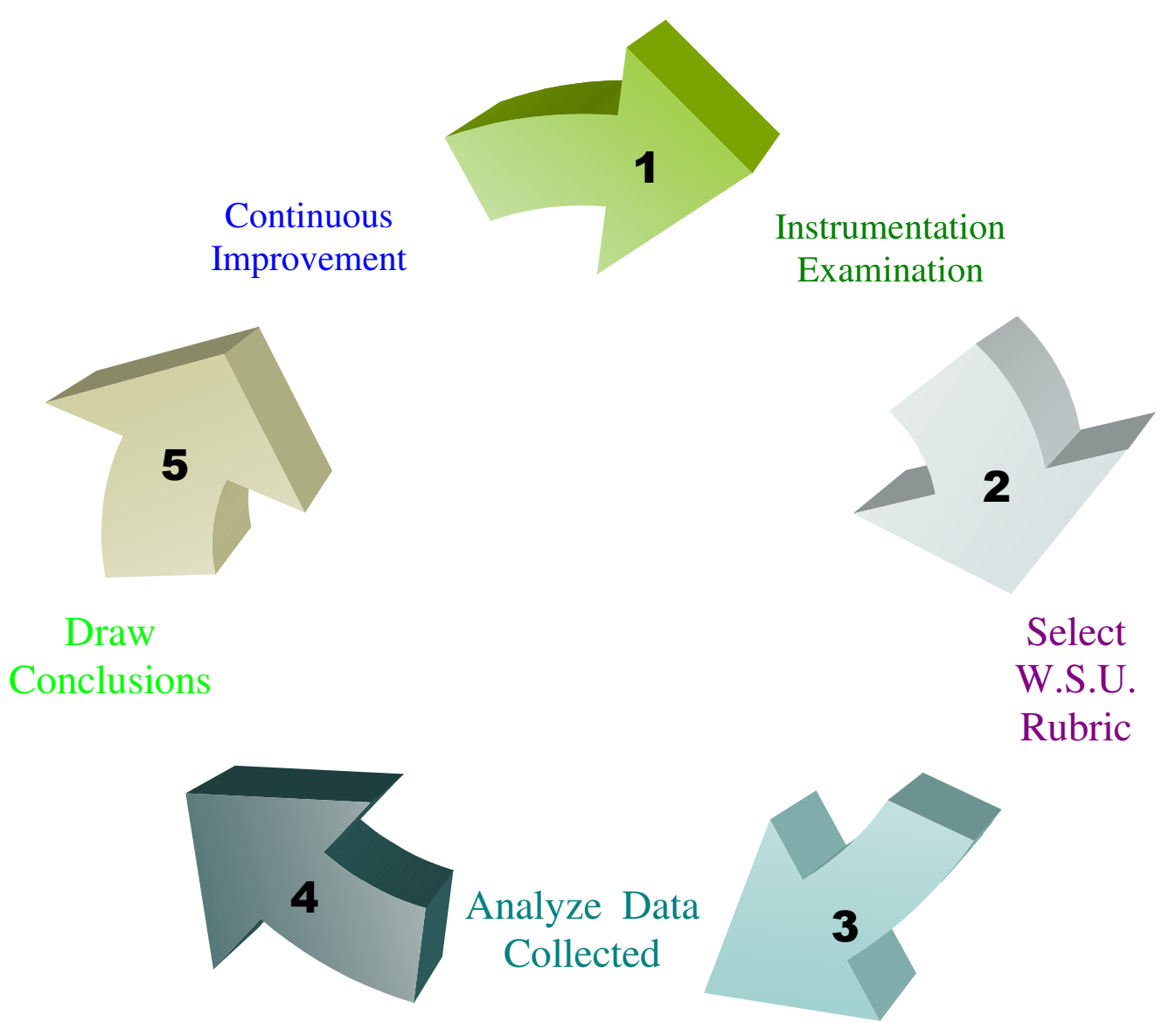

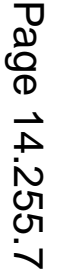


APPENDIX B: (Rubrics courtesy of W S U, Pullman, WA)

\section{Rubrics based on Likert Scale}

5

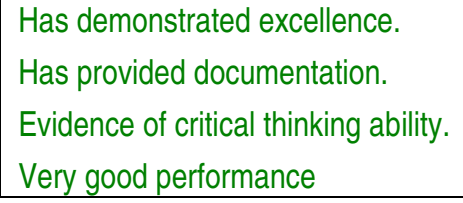

3

Has demonstrated competency.
Adequate documentation.
Critical thinking ability exists.
Acceptable performance.

Poor, unacceptable performance.

Lacks critical thinking ability.
Has analyzed important data precisely. Has answered key questions correctly. Has addressed problems effectively. Has evaluated material with proper insight. Has used deductive reasoning skills. Has used inductive reasoning skills. Has employed problem solving skills. Has discussed consequences of decisions. Has been consistent with inference.

Data analysis can be improved. More effort to address key questions. Need to address problems effectively. Expand on evaluating material. Improve deductive reasoning skills. Improve inductive reasoning skills. Problem solving skills need honing. Must discuss consequences of decisions.

Has been vague with inference.

Absence of analytical skills.

Answers questions incorrectly.

Addresses problems superficially.

Lacks documentation.

Inability to evaluate material.

Shows no deductive reasoning power.

Inductive reasoning power non existent.

Poor problem solving skills

Unaware of consequences of decisions.

Unable to draw conclusions. 
APPENDIX C : Matrix Generated using W.S.U. Rubrics (Subject: Instrumentation)

Laboratory Instrumentation Assessment

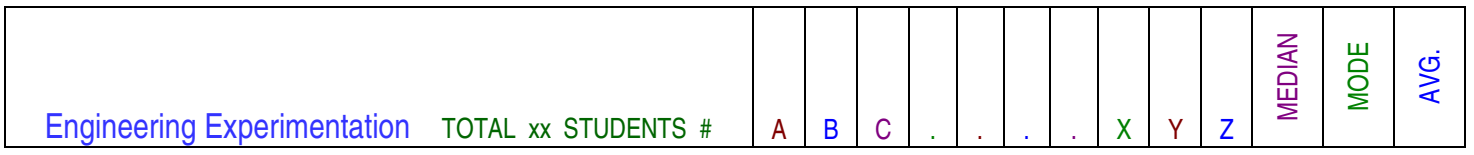

THE CRITICAL THINKING RUBRIC

RUBRIC COURTESY OF W. S. U.

WASHINGTON STATE UNIVERSITY

PULLMAN, WA. 99164.

LIKERT SCALE WEIGHT DISTRIBUTION:

(1: Strongly Disagree; 5 : Strongly Agree)

\begin{tabular}{|c|c|c|c|c|c|c|c|c|c|c|}
\hline Data Acquisition and Mathematical Analysis & 4 & 4 & 3 & . & . & . & . & 4 & 3 & 3 \\
\hline Mechanical Transducers and Instrumentation & 3 & 4 & 5 & . & . & . & . & 5 & 5 & 5 \\
\hline Heat Conduction Gages, Principles of Heat transfer & 5 & 4 & 3 & . & . & . & . & 3 & 4 & 5 \\
\hline Importance of Electrical and Electronic Instruments & 3 & 3 & 5 & . & . & . & . & 4 & 3 & 4 \\
\hline Ability to use Electromechanical Transducers & 3 & 3 & 5 & . & . & . & . & 5 & 4 & 4 \\
\hline Skillful use of Potentiometers and L.V.D.T.s & 4 & 4 & 5 & . & . & . & . & 5 & 4 & 5 \\
\hline Knowledge of Gages and Manometers & 4 & 3 & 4 & . & . & . & . & 3 & 4 & 3 \\
\hline
\end{tabular}

Data Collected by : Mysore Narayanan.

The data collected are ordinal: they have an inherent order or sequence, but one cannot assume that the respondent means that the difference between agreeing and strongly agreeing is the same as between agreeing and being undecided. Descriptive Techniques (Likert Evaluation Cookbook 2004)

Summarize using a median or a mode (not a mean); the mode is probably the most suitable for easy interpretation.

Express variability in terms of the range or inter quartile range (not the standard deviation).

Display the distribution of observations in a dotplot or a barchart (it can't be a histogram, because the data is not continuous). 


\section{APPENDIX D:}

Rubrics courtesy of Washington State University, Pullman, WA.

Subject Studied : Engineering Experimentation and Instrumentation

Partial list of topics observed

1. Data Acquisition and Mathematical Analysis

2. Mechanical Transducers and Instrumentation

3. Heat Conduction Gages, Principles of Heat transfer

4. Importance of Electrical and Electronic Instruments

5. Ability to use Electromechanical Transducers

6. Skillful use of Potentiometers and L.V.D.T.s

7. Knowledge of Gages and Manometers

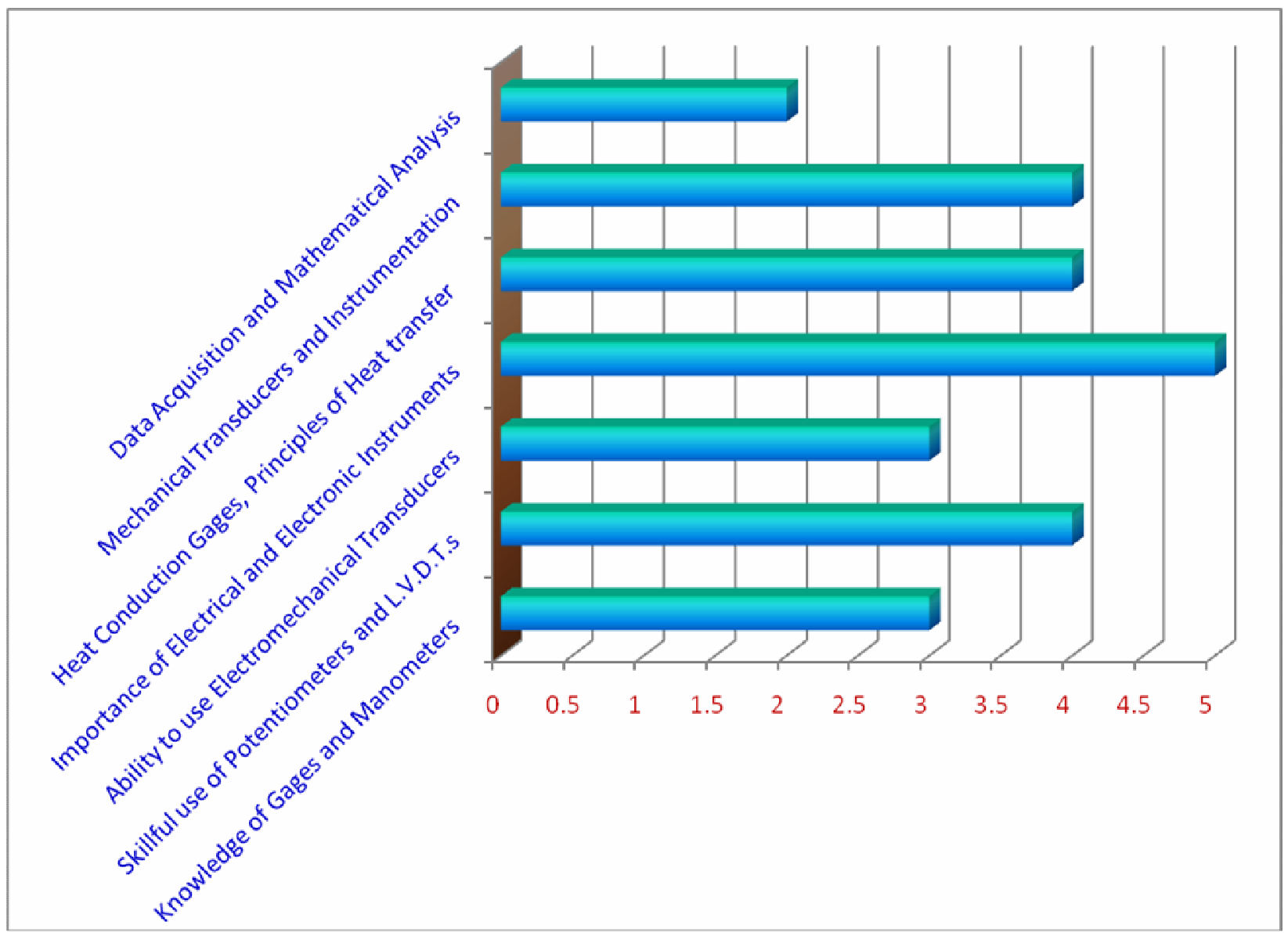


References:

A.C.P. (2004). Learning Reconsidered: A campus-wide focus on the student experience. The American College Personnel Association: The National Association of Student Personnel Administrators.

AAHE Assessment Forum. (1992). Principles for good practice for assessing students' learning. Washington, DC: American Association for Higher Education.

Angelo, Thomas A. and Cross, Patricia K. (1993): Classroom Assessment Techniques. 2nd Edition. San Francisco: Jossey-Bass Publishers.

Barrows, Howard S (2000). Problem-Based Learning Applied to Medical Education. Springfield, IL: SIU School of Medicine.

Boud, D J (1985). Problem-based learning in perspective, in Boud, D J (ed) Problem-Based Learning in Education for the Professions. Sydney: Higher Education Research and Development Society of Australasia.

Boud, D., Feletti, G. (1991). The Challenge of Problem-based Learning. London: Kogan Page.

Bresciani, M. (2003, January 9-11) NASPA advanced assessment workshop, Georgia State

University.

Dick, W. \& Cary, L. (1996). The systematic design of instruction. New York: HarperCollins Publishers.

Engel, C E (1991). Not Just a Method But a Way of Learning, in Boud D and Feletti, G (eds) The Challenge of Problem Based Learning. London: Kogan Page.

Keefe, J. W. (1991). Learning style: Cognitive and thinking skills. Reston, VA: National Association of Secondary School Principals.

Keefe, J. W. (1988). Profiling and utilizing learning style. Reston, VA: National Association of Secondary School Principals.

Keefe, J. W. (1987). Theory and practice. Reston, VA: National Association of Secondary School Principals.

Narayanan, Mysore (2003). Instrumentation for A New Strength of Materials Laboratory at Miami University. Proceedings of the 2003 American Society for Engineering Education Annual Conference \& Exposition $@$ 2003, American Society for Engineering Education.

Narayanan, Mysore (2007). Pedagogy for the development of an Instrumentation Laboratory. Proceedings of the 2007 American Society for Engineering Education Annual Conference \& Exposition @ 2007, American Society for Engineering Education.

Narayanan, Mysore (2007) Assessment of Perceptual Modality Styles. Proceedings of $114^{\text {th }}$ ASEE National Conference, June 24-27, Hilton Hawaiian Village, Honolulu, Hawaii.

Narayanan, Mysore (2008). Assessment of Water Conservation Education. World Environmental and Water Resources Congress 2008, May 12- 16, 2008. Honolulu, Hawaii. (ASCE.)

Nickerson, R.S., Perkins, D.N., Smith, E.E. (1985). The Teaching of Thinking. Lawrence Erlbaum Associates, Hillsdale, NJ, London.

Pascarella, E. T. \& Terenzini, P. T. (1991). How college affects students: Findings and insights from 20 years of research. San Francisco: Jossey-Bass. 
Rowntree, D.(1977). Assessing Students: How Shall We Know Them? New York: Harper and Row Publishers.

Wilkerson, L., \& Gijselaers, W.H. (Eds.) (1996). Bringing Problem-Based Learning to Higher Education: Theory and Practice. San Francisco: Jossey-Bass Publishers

Woods, Donald R. (1994). Problem-based Learning: How to Gain the Most from PBL. Hamilton, Ontario, Canada: Donald R. Woods Publisher.

[ http://www.cmu.edu/teaching/principles/learning.html ] 